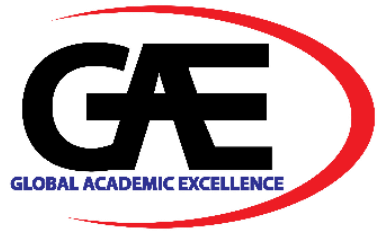

\title{
VIDEO-BASED LEARNING ON STATISTICAL TOPICS AMONG FOUNDATION STUDENTS IN UNIVERSITI MALAYSIA SABAH: AN IN-DEPTH ANALYSIS OF SATISFACTION
}

\author{
Nurliyana Juhan ${ }^{1}$, Che Haziqah Che Hussin ${ }^{2 *}$, Mohd Azrul Abdul Rajak ${ }^{3}$, Sitty Nur Syafa Bakri ${ }^{4}$ \\ 1 Preparatory Centre for Science and Technology, Universiti Malaysia Sabah, Sabah, Malaysia \\ Email: liyana87@ums.edu.my \\ 2 Preparatory Centre for Science and Technology, Universiti Malaysia Sabah, Sabah, Malaysia \\ Email: haziqah@ums.edu.my \\ 3 Preparatory Centre for Science and Technology, Universiti Malaysia Sabah, Sabah, Malaysia \\ Email: azrulajak88@ums.edu.my \\ 4 Preparatory Centre for Science and Technology, Universiti Malaysia Sabah, Sabah, Malaysia \\ Email:syafa@ums.edu.my \\ Corresponding Author
}

\section{Article Info:}

\section{Article history:}

Received date: 11.09 .2021

Revised date: 10.10 .2021

Accepted date: 15.11.2021

Published date: 30.11 .2021

To cite this document:

Juhan, N., Hussin, C. H. C., Abdul Rajak, M. A., \& Bakri, S. N. S (2021). Video-Based Learning on Statistical Topics Among Foundation Students in Universiti Malaysia Sabah: An InDepth Analysis of Satisfaction. Journal of Information System and Technology Management, 6 (23), 118127.

DOI: $10.35631 / J I S T M .623010$

\begin{abstract}
:
Video-based learning has recently gained popularity as one of the numerous choices in remote education approaches during the pandemic that differs from conventional face-to-face lecture-based education. However, video-based learning and online teaching were different and quite challenging for students, especially when studying statistics and it is conducted remotely. Therefore, the purpose of this study is to assess student satisfaction with video-based learning on statistical topics. This study was conducted with 357 foundations of science students in the Preparatory Centre for Science and Technology, Universiti Malaysia Sabah. An independently developed questionnaire focusing on four factors, namely teaching, learning, technology, and skills, was given to students, and the results were then analysed. Based on the questionnaire the range of the mean is $4.54-4.87$, which suggested that the video-based learning on statistical topics had an overall positive outcome on student satisfaction. Mostly, students scored higher mean scores for the items under the factor of teaching than for the items under the other three factors. This study also discovered that video-based learning relied on teaching, learning, and skills rather than the technology itself. However, technology continues to be a critical platform for educators' educational activities. Therefore, this study demonstrated the critical significance of meeting the rising demand for online education, particularly video-based learning, while still providing a compelling student learning experience.
\end{abstract}


Special Issue: Foundation Program Education Post-Covid-19: Issues and Opportunities

\section{Introduction}

Over 1.2 billion students worldwide have been impacted by school and university closures as a result of the coronavirus disease 2019 (COVID-19) pandemic (Araújo et al., 2020; Fatani, 2020). This closure had a significant impact on students' educational activities, forcing the school to relocate the course of study online and consider new ways to remote education. To facilitate students' education, educators moved from in-person to remote education. Videobased learning has recently gained popularity as one of the numerous choices in remote education approaches that differ from conventional face-to-face lecture-based education (Pal \& Patra, 2020; Suryandari \& Singgih, 2021). However, video-based technology and online teaching were different and quite challenging for several educators (Flack et al., 2021). The majority of educators are unfamiliar with online learning tools; thus, they experience difficulty in utilising them (Riggs, 2020).

In online education, the educators faced four significant obstacles, including showing teaching abilities in an online classroom, addressing their leadership roles, developing connections with students, and providing technical assistance as some of the students are facing limited internet quota and unstable internet networks (Fatani, 2020; Philipsen et al., 2019). Simultaneously, it's worth noting that students frequently lack the skills and knowledge necessary for metacognition learning video content especially those that involve mathematical algorithms and calculations to be analysed throughout the home learning process (Mulenga \& Marbán, 2020). Some students lacked a strong commitment and enthusiasm in studying certain subjects through online education. They demonstrated that studying mathematics specifically statistics are challenging for them, especially when it is conducted remotely (Suliani et al., 2021). Many students continue to view statistics as a difficult topic because it is abstract, logical, methodical, and filled with perplexing symbols and formulae. Students frequently experience anxiety when they are required to master statistics (Juniati \& Budayasa, 2020). As a result, online learning material and methods that approximate face-to-face instruction is required to assist students in studying statistics.

With these obstacles in mind, the majority of educators believe that a feasible option for adopting online learning for statistical subjects is to use video as the medium for delivering knowledge rather than video conferences or modules. In comparison to video conferences, video is said to be capable of providing content more effectively than modules and consuming less internet quota (Jarrah et al., 2021; Suliani et al., 2021). In response to the pandemic that requires a remote learning programme, video application provides an alternate way for students to study independently at home. It transforms the complexities of conventional education into online video-based learning. Moreover, it was designed to stimulate students' interest in learning and provide a chance for them to enhance their understanding and numeracy skills while learning mathematics and statistics online (Apriliawan \& Parmiti, 2021). It's unsurprising that a growing number of educators are exploring video-based learning technologies nowadays. 
Volume 6 Issue 23 (November 2021) PP. 118-127

DOI: 10.35631/JISTM.623010

Special Issue: Foundation Program Education Post-Covid-19: Issues and Opportunities Video was chosen as a learning medium because it gives an excellent audio-visual presentation of the information and it provides a realistic learning model that enables students to learn in a realistic setting (Yükselir \& Kömür, 2017). Specifically, by including video on problem-based learning. The problem-based learning approach is a type of education that utilises real-world situations and places a premium on problem identification and problem-solving abilities which is incredibly relevant to statistics (Pinatih et al., 2021).

Despite all the obstacles, educators still needed to enable video-based learning successfully while maintaining a high-quality, genuine learning experience with a high percentage of student satisfaction (Tur et al., 2020). This is also consistent with technological advancements beyond the 4.0 industrial revolution. Therefore, the purpose of this study is to assess student satisfaction with video-based learning on statistical topics.

\section{Material \& Method}

\section{Sample}

This study was conducted with 357 foundation of science students in the Preparatory Centre for Science and Technology, Universiti Malaysia Sabah who took the Algebra, Calculus, Statistics and Probability course in the second semester of session 2020/2021.

\section{Procedure}

The procedure of video-based learning is as follows. Initially, for the pre-lecture activity, the lecturer provided lecture notes and relevant reference materials a few days ahead of the lecture for pre-lecture learning. There were three main statistical topics involved in this video-based learning namely Descriptive data, Discrete random variable, and Binomial distribution. On the day of the lecture, the students can independently access the lecture videos on Smartv3ums, a learning management system provided by the university (Figure 1).
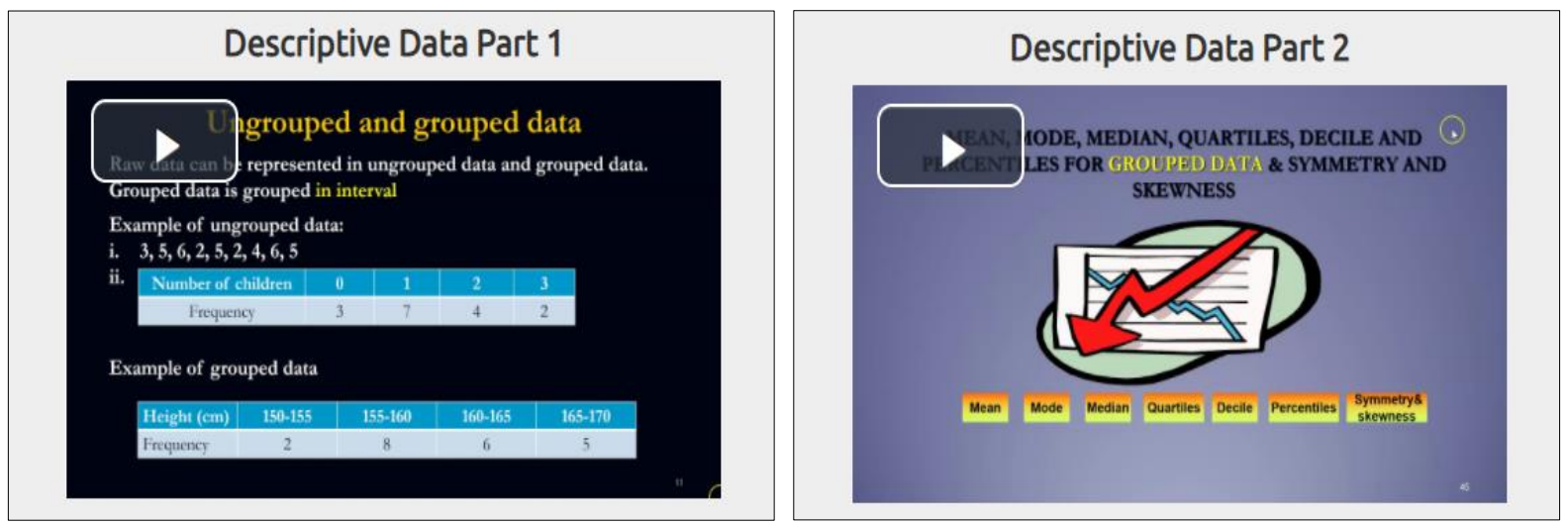

Figure 1: The Lecture Videos on Smartv3ums

All the videos are accessible till the end of the semester. A week after the video-based learning for each topic, the students will have a tutorial whereby the lecturer or the tutor facilitated students' full discussion on the topic and provided additional explanations on what was not explained by the students. At the end of the video-based learning, a survey on satisfaction levels was conducted to elicit feedback from students on the video-based learning. 


\section{Instrumentation}

Special Issue: Foundation Program Education Post-Covid-19: Issues and Opportunities

In this study, a questionnaire was independently developed to assess student satisfaction with video-based learning on statistical topics. The measurement tool consisted of a total of thirteen questions consisting of four factors namely teaching, learning, technology and skills corresponding to the results of the factor analysis that was conducted for validity verification. A five-point Likert scale was applied, with a range of 1 (strongly disagree) to 5 (strongly agree). The data were collected through the well-known online survey tool Google Form.

\section{Ethical Concerns}

In the survey of the satisfaction level on video-based learning, only data from students who were fully informed of the survey's objective were analysed, and students' personal information remained protected. This was conducted according to the guidelines from a previous study (Lugo-Armenta \& Pino-Fan, 2021).

\section{Statistical Analysis}

The Statistical Package for Social Science (SPSS) version 27.0 and Minitab 16 were used to analyse the data. Among the analyses conducted were estimations of the questionnaire items' means, standard deviations, factor loadings, and reliability coefficients.

\section{Results \& Discussion}

A total of 357 student responses were received. Table 1 showed the results of the factor analysis that was conducted for validity verification. Four factors on teaching (three items), learning (four items), technology (three items) and skills (three items) explained $85.15 \%$ of the total variation. The reliability value (Cronbach's $\alpha$ coefficient) of each factor was 0.869 for the factor of teaching, 0.862 for the factor of learning, 0.877 for the factor of technology and 0.891 for the factor of skills. The alpha coefficients for the four factors suggested that the items for each factor have relatively high internal consistency.

Table 1. Factor Loading for Student Satisfaction on Video-Based Learning

\begin{tabular}{lccccc}
\hline \multicolumn{1}{c}{$\begin{array}{c}\text { Questionnaire } \\
\text { Item }\end{array}$} & Teaching & Learning & Technology & Skills & Reliability \\
\cline { 2 - 5 } & Factor 1 & Factor 2 & Factor 3 & Factor 4 & $(\boldsymbol{\alpha})$ \\
\hline $\begin{array}{l}\text { 1. The lecturer had } \\
\text { described the topic } \\
\text { outline at the }\end{array}$ & 0.852 & 0.431 & 0.221 & 0.132 & \\
$\begin{array}{l}\text { beginning of the } \\
\text { lecture video. }\end{array}$ & & & & & \\
\hline $\begin{array}{l}\text { 2. The lecturer was } \\
\text { able to arouse } \\
\text { students' interest } \\
\text { and motivation in } \\
\text { the topic. }\end{array}$ & 0.867 & 0.412 & 0.255 & 0.165 & \\
\hline $\begin{array}{l}\text { 3. The lecturer } \\
\text { explained the topic } \\
\text { clearly and } \\
\text { effectively. }\end{array}$ & 0.871 & 0.498 & & & \\
\hline
\end{tabular}


Volume 6 Issue 23 (November 2021) PP. 118-127

DOI: 10.35631/JISTM.623010

4. The videos

Special Issue: Foundation Program Education Post-Covid-19: Issues and Opportunities

helped me learn

and understand the

0.321

0.880

0.211

0.109

statistical topics

easier.

5. More video-

based learning for

statistical topics in

0.367

0.851

0.202

0.198

0.877

the future.

6 . The video-based

learning was

interesting and

0.3481

0.863

0.232

0.157

intellectually

stimulating.

7. The videos'

quality

(audio/visual) was

0.391

0.212

0.887

0.192

good.

8. The videos'

platform was

suitable (eg.

0.412

0.237

0.843

0.167

0.869

Smartv3ums/

Youtube).

9. The videos'

duration was

0.387

0.288

0.865

0.174

suitable.

\begin{tabular}{|c|c|c|c|c|c|}
\hline $\begin{array}{l}\text { 10. Enhancement } \\
\text { of digital skills. }\end{array}$ & 0.311 & 0.461 & 0.219 & 0.884 & \multirow{3}{*}{0.862} \\
\hline $\begin{array}{l}\text { 11. Enhancement } \\
\text { of numeracy skills }\end{array}$ & 0.379 & 0.489 & 0.276 & 0.893 & \\
\hline $\begin{array}{l}\text { 12. Enhancement } \\
\text { of problem-solving } \\
\text { skills }\end{array}$ & 0.312 & 0.441 & 0.203 & 0.807 & \\
\hline $\begin{array}{l}\text { Percentage of } \\
\text { variance }\end{array}$ & 27.146 & 22.978 & 18.043 & 16.978 & \\
\hline
\end{tabular}

The results for student satisfaction level of video-based learning on statistical topics can be categorised into four different factors specifically teaching, learning, technology and skills as shown in Table 2 to Table 5. According to the results for each item in Table 2, the factor of teaching recorded $4.80( \pm 0.42)$ for the overall mean. In detail, item 2 where the lecturer was able to arouse students' interest and motivation in the topic showed the highest mean score of 4.87. This is followed by item 3 where the lecturer explained the topic clearly and effectively and item 1 where the lecturer had described the topic outline at the beginning of the lecture video with a mean score of 4.82 and 4.71 respectively. 
Volume 6 Issue 23 (November 2021) PP. 118-127

DOI: 10.35631/JISTM.623010

Special Issue: Foundation Program Education Post-Covid-19: Issues and Opportunities The result of this study is supported by previous studies whereby Mathematics and Statistics are somehow known as challenging subjects and due to relatively difficult learning certain topics, the educator's enthusiasm and the way the topic was explained in the video can be a factor to arouse students' interest and motivation in the topic (Fatani, 2020; Lugo-Armenta \& Pino-Fan, 2021). This is done in an attempt to create an atmosphere comparable to that of studying in a lecture hall, when the lecturer educates students on the subject being delivered (Tabakin et al., 2021).

Table 2. Descriptive Statistics for Students Satisfaction on Video-Based Learning Based on The Teaching Factor.

\begin{tabular}{|c|c|c|}
\hline Questionnaire Item & $\begin{array}{c}\text { Mean } \\
\text { (Standard } \\
\text { Deviation) }\end{array}$ & $\begin{array}{c}\text { Overall } \\
\text { Mean } \\
\text { (Standard } \\
\text { Deviation) }\end{array}$ \\
\hline $\begin{array}{l}\text { 1. The lecturer had described the topic outline at the } \\
\text { beginning of the lecture video. }\end{array}$ & $4.71(0.48)$ & \multirow{3}{*}{$4.80(0.42)$} \\
\hline $\begin{array}{l}\text { 2. The lecturer was able to arouse students' interest and } \\
\text { motivation in the topic. }\end{array}$ & $4.87(0.35)$ & \\
\hline $\begin{array}{l}\text { 3. The lecturer explained the topic clearly and } \\
\text { effectively. }\end{array}$ & $4.82(0.42)$ & \\
\hline
\end{tabular}

As for Table 3, the factor of learning recorded $4.72( \pm 0.47)$ for the overall mean. In detail, item 4 where the videos helped the students learn and understand the statistical topics easier showed the highest mean score of 4.81 . This is followed by item 6 where the students suggested that the video-based learning was interesting and intellectually stimulating with a mean score of 4.74. The result of this study is in line with Suryandari \& Singgih (2021), where video was an effective learning medium that was widely used by educators and students. Learning through videos makes it easy for students to understand as they can pause or repeat specific parts that they encounter difficulty and watch on the steps or solutions given appropriately. Through this medium, they found that the learning process is enjoyable and stimulating as they are able to control the process according to their own pace (Pinatih et al., 2021). Unsurprisingly, due to all the aspects discussed above, the mean score is quite high for item 5 where students are excited to have more video-based learning in the future for statistical topics.

Table 3. Descriptive Statistics for Students Satisfaction on Video-Based Learning Based on The Learning Factor.

\begin{tabular}{lll}
\hline \multicolumn{1}{c}{ Questionnaire Item } & $\begin{array}{c}\text { Mean } \\
\text { (Standard } \\
\text { Deviation) }\end{array}$ & $\begin{array}{c}\text { Overall } \\
\text { Mean } \\
\text { (Standard } \\
\text { Deviation) }\end{array}$ \\
$\begin{array}{llll}\text { 4. The videos helped me learn and understand the } \\
\text { statistical topics easier. }\end{array}$ & $4.81(0.43)$ & \\
\cline { 1 - 2 } $\begin{array}{l}\text { 5. More video-based learning for statistical topics in the } \\
\text { future. }\end{array}$ & $4.61(0.49)$ & \\
\cline { 1 - 2 } $\begin{array}{l}\text { 6. The video-based learning was interesting and } \\
\text { intellectually stimulating. }\end{array}$ & $4.74(0.48)$ & \\
\hline
\end{tabular}


While in Table 4, the factor of technology recorded $4.65( \pm 0.51)$ for the overall mean. In detail, students rated the highest mean score for item 7 where the videos' quality (audio/visual) was good with a mean score of 4.72 . This is followed by item 9 where the videos' duration was suitable and item 8 where the videos' platform was suitable with a mean score of 4.63 and 4.61 respectively. This study's outcome is consistent with Pal \& Patra (2020) and Turan \& Cetintas (2019) where the quality and duration of the video play a big role in making the learning process enjoyable and beneficial. Moreover, for the duration of the video, excessive screen time is not only bad for students' health, but it can also cause eye fatigue and a lack of attention. This element of video-based learning was not that significant before the pandemic, as students attended regular physical classes. However, during the pandemic, when lectures are conducted entirely online, the duration of each video-based lecture must be adjusted to prevent students from becoming exhausted and to ensure that their learning remains effective (Pal \& Patra, 2020). As for the video's platform, students rated that Smartv3ums and Youtube as suitable platforms as both were commonly used by them and easy access.

Table 4. Descriptive Statistics for Students Satisfaction on Video-Based Learning Based on The Technology Factor.

\begin{tabular}{|c|c|c|}
\hline Questionnaire Item & $\begin{array}{c}\text { Mean } \\
\text { (Standard } \\
\text { Deviation) }\end{array}$ & $\begin{array}{c}\text { Overall } \\
\text { Mean } \\
\text { (Standard } \\
\text { Deviation) }\end{array}$ \\
\hline 7. The videos' quality (audio/visual) was good. & $4.72(0.46)$ & \multirow{3}{*}{$4.65(0.51)$} \\
\hline $\begin{array}{l}\text { 8. The videos' platform was suitable (eg. } \\
\text { Smartv3ums/Youtube). }\end{array}$ & $4.61(0.53)$ & \\
\hline 9. The videos' duration was suitable. & $4.63(0.53)$ & \\
\hline
\end{tabular}

According to the results for each item in Table 5, the factor of skills recorded $4.64( \pm 0.52)$ for the overall mean. In detail, item 11 which is the enhancement of numeracy skills showed the highest mean score of 4.72. This is followed by item 12 which is the enhancement of problemsolving skills and item 10 which is the enhancement of digital skills with a mean score of 4.67 and 4.54 respectively. The result of this study is supported by Apriliawan \& Parmiti (2021) and Kellems et al. (2020) where learning mathematics or statistics through video improved numeracy as well as problem-solving skills. While Bernacki et al. (2020) stated that any learning process which involved internet use and digital tools has a significant effect in enhancing digital skills among the learners.

Table 5. Descriptive Statistics for Students Satisfaction on Video-Based Learning Based on The Skills Factor.

\begin{tabular}{llll}
\hline Questionnaire Item & $\begin{array}{c}\text { Mean } \\
\text { (Standard } \\
\text { Deviation) }\end{array}$ & $\begin{array}{c}\text { Overall } \\
\text { Mean } \\
\text { (Standard } \\
\text { Deviation) }\end{array}$ \\
\cline { 1 - 2 } 10. Enhancement of digital skills & $4.54(0.56)$ & \multirow{2}{*}{$4.64(0.52)$} \\
\cline { 1 - 2 } 11. Enhancement of numeracy skills & $4.72(0.49)$ & \\
\cline { 1 - 2 } 12. Enhancement of problem-solving skills & $4.67(0.50)$ & \\
\hline
\end{tabular}


Volume 6 Issue 23 (November 2021) PP. 118-127

DOI: 10.35631/JISTM.623010

Special Issue: Foundation Program Education Post-Covid-19: Issues and Opportunities Figure 2 showed the overall results on the mean score for item 1 until item 12. The range of the mean is $4.54-4.87$, which suggested that the video-based learning on statistical topics had an overall positive outcome on student satisfaction. Most students scored higher means for the items under the factor of teaching than the items under the other three factors. This indicated that students were satisfied with the teaching provided by the lecturer despite facing challenges with some technical issues during the learning process. This study also discovered that videobased learning relied on teaching, learning and skills rather than the technology itself. However, technology continues to be a critical platform for educators' educational activities. Additionally, this study demonstrated the critical significance of meeting the rising demand for online education, particularly video-based learning, while still providing a compelling student learning experience.

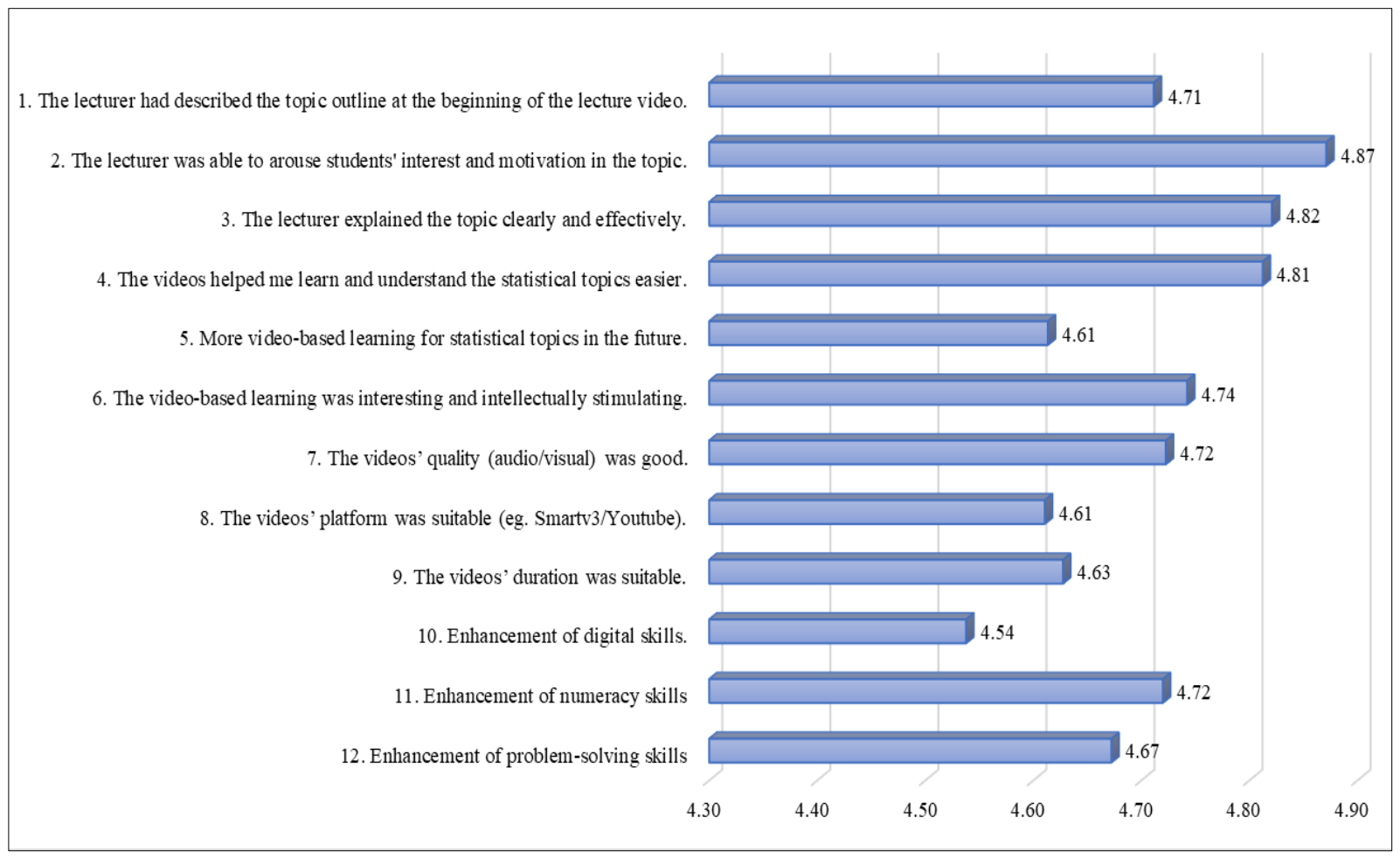

Figure 2: The Mean Score for Item 1-12

\section{Conclusion}

The pandemic of COVID-19 led the educational system to embark on a new age of online education. This study examined the novel experience of video-based learning specifically on statistical topics on foundation students. It provided insight into the strengths and weaknesses of student satisfaction on the factor of teaching, learning, technology, and skills involved in video-based learning. Overall, video-based learning increased student satisfaction, despite the fact that it depended on teaching, learning and skills rather than the technology itself.

\section{References}

Apriliawan, P. A., \& Parmiti, D. P. (2021). Improve Students' Numeracy Skills Using Learning Videos. International Journal of Elementary Education, 5(2), 256-267. 
Volume 6 Issue 23 (November 2021) PP. 118-127

DOI: 10.35631/JISTM.623010

Special Issue: Foundation Program Education Post-Covid-19: Issues and Opportunities

Araújo, F. J. de O., de Lima, L. S. A., Cidade, P. I. M., Nobre, C. B., \& Neto, M. L. R. (2020). Impact Of Sars-Cov-2 And Its Reverberation In Global Higher Education And Mental Health. Psychiatry Research, 288, 112977.

Bernacki, M. L., Vosicka, L., Utz, J. C., \& Warren, C. B. (2020). Effects of Digital Learning Skill Training on the Academic Performance of Undergraduates in Science and Mathematics. Journal of Educational Psychology. https://doi.org/10.1037/EDU0000485

Fatani, T. H. (2020). Student satisfaction with videoconferencing teaching quality during the COVID-19 pandemic. BMC Medical Education, 20(1), 1-8.

Flack, C. B., Walker, L., Bickerstaff, A., Earle, H., \& Margetts, C. (2021). Educator perspectives on the impact of COVID-19 on teaching and learning in Australia and New Zealand.

Jarrah, A., Almarashdeh, H., Almarashdi, H., \& Jarrah, A. M. (2021). Mathematics Distance Learning amid the COVID-19 Pandemic in the UAE: High School Students' Perspectives. International Journal of Learning, Teaching and Educational Research, 20(1), 292-307.

Juniati, D., \& Budayasa, I. K. (2020). Working memory capacity and mathematics anxiety of mathematics undergraduate students and its effect on mathematics achievement. Journal for the Education of Gifted Young Scientists, 8(1), 279-291.

Kellems, R. O., Eichelberger, C., Cacciatore, G., Jensen, M., Frazier, B., Simons, K., \& Zaru, M. (2020). Using Video-Based Instruction via Augmented Reality to Teach Mathematics to Middle School Students With Learning Disabilities: Journal of Learning Disabilities, 53(4), 277-291. https://doi.org/10.1177/0022219420906452

Lugo-Armenta, J. G., \& Pino-Fan, L. R. (2021). Inferential statistical reasoning of math teachers: Experiences in virtual contexts generated by the COVID-19 pandemic. Education Sciences, 11(7), 363. https://doi.org/10.3390/educsci11070363

Mulenga, E. M., \& Marbán, J. M. (2020). Is COVID-19 the Gateway for Digital Learning in Mathematics Education? Contemporary Educational Technology, 12(2), ep269.

Pal, D., \& Patra, S. (2020). University Students' Perception of Video-Based Learning in Times of COVID-19: A TAM/TTF Perspective. International Journal of Human-Computer Interaction, 37(10), 903-921. https://doi.org/10.1080/10447318.2020.1848164

Philipsen, B., Tondeur, J., Pareja Roblin, N., Vanslambrouck, S., \& Zhu, C. (2019). Improving teacher professional development for online and blended learning: a systematic metaaggregative review. Educational Technology Research and Development 2019 67:5, 67(5), 1145-1174. https://doi.org/10.1007/S11423-019-09645-8

Pinatih, I. G. A. D. P., Nitiasih, P. K., Budiarta, luh G. R., \& Adnyayanti, N. L. P. E. (2021). BOOSTING STUDENTS' SPEAKING SKILL IN THE PANDEMIC ERA USING PROBLEM BASED LEARNING VIDEO. PROJECT (Professional Journal of English Education), 4(5), 893-899. https://doi.org/10.22460/PROJECT.V4I5.P893-899

Riggs, S. (2020). Thrive Online: A New Approach to Building Expertise and Confidence as an online educator. Stylus Publishing, LLC.

Suliani, M., Juniati, D., \& Ulfah, F. (2021). Learning Mathematics in Madrasah Aliyah Muhammadiyah 2 Banjarmasin during the covid-19 pandemic era. Journal of Physics: Conference Series, 1747(1), 012018. https://doi.org/10.1088/17426596/1747/1/012018

Suryandari, \& Singgih, S. (2021). Video-based learning for "learning from home" solution in pandemic. Journal of Physics: Conference Series, 1760(1), 012011. 
Volume 6 Issue 23 (November 2021) PP. 118-127

DOI: 10.35631/JISTM.623010

Special Issue: Foundation Program Education Post-Covid-19: Issues and Opportunities

Tabakin, A. L., Patel, H. V., \& Singer, E. A. (2021). Lessons Learned from the COVID-19 Pandemic: A Call for a National Video-Based Curriculum for Urology Residents. Journal of Surgical Education, 78(1), 324-326. https://doi.org/10.1016/j.jsurg.2020.07.013

Tur, G., Havemann, L., Marsh, D., Keefer, J. M., \& Nascimbeni, F. (2020). Becoming an open educator: towards an open threshold framework. Research in Learning Technology, 28, 2020. https://doi.org/10.25304/RLT.V28.2338

Turan, Z., \& Cetintas, H. B. (2019). Investigating university students' adoption of video lessons. Https://Doi.Org/10.1080/02680513.2019.1691518, 35(2), 122-139.

Yükselir, C., \& Kömür, S. (2017). Using Online Videos to Improve Speaking Abilities of EFL Learners. Online Submission, 3(5), 255-266. 